www.nature.com/clinicalpractice/gasthep

\title{
Imaging and management of rectal cancer
}

Julia K LeBlanc

Nature Clinical Practice Gastroenterology \& Hepatology (2007) 4: 665-676 [doi:10.1038/ncpgasthep0977]

\section{CORRIGENDUM}

In the December 2007 issue, in the Review by LeBlanc, the first sentence of the fourth paragraph of the Introduction on page 665 was found to be in need of clarification. The sentence should read "Transanal excision for stage T2 tumors (i.e. tumors that invade into but not through the muscularis propria) is possible but generally not accepted and is performed in select cases of stage T1 tumors (i.e. tumors that invade into but not through the submucosa)." doi:10.1038/ncpgasthep1063 